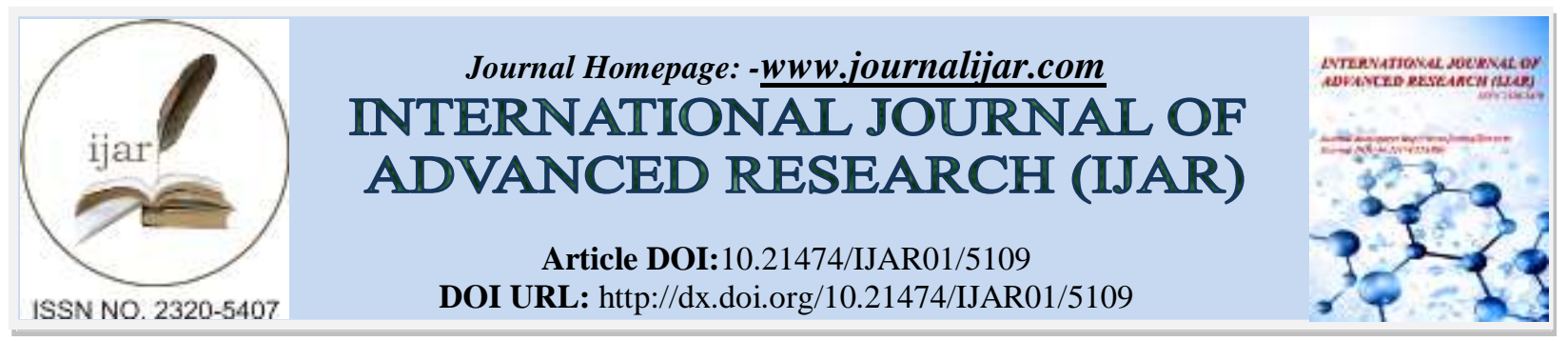

RESEARCH ARTICLE

\title{
APPEARANCE STATUS AND NARCISSISM AMONG ADOLESCENTS AND YOUNG ADULTS.
}

\section{Geetesh Kumar Singh ${ }^{1}$ and Dr. Richa Rani Yadav ${ }^{2}$.}

1. M.A. in Clinical Psychology from Department of Psychology, DAV PG College, B.H.U., Varanasi, India.

2. Associate Professor, Department of Psychology, DAV PG College, B.H.U., Varanasi, India.

\section{Manuscript Info}

Manuscript History

Received: 08 June 2017

Final Accepted: 10 July 2017

Published: August 2017

Key words:-

Narcissism, Appearance Status, Gender Status, Age Status.

\begin{abstract}
To date, face research has focused largely on the appearance status (parlor going tendencies) and narcissism, how these variables are affecting each other. Appearance status have two basics dimensions one is associated with the parlor (Salon or Beauty Parlor) going people and other is associated with non-parlor going people, here we are interested to see whether the narcissism is high or low in parlor going people or non-parlor going people. The term narcissism involves grandiosity, a lack of empathy for other people, and a need for admiration. People with this condition are frequently described as arrogant, self-centered, manipulative, and demanding. They may also concentrate on grandiose fantasies (e.g. success, beauty, brilliance) and may be convinced that they deserve special treatment. These characteristics typically begin in early adulthood and must be consistently evident in multiple contexts, such as at work and in relationships. Finding reveals that narcissism is high in the people having parlor going tendencies, this study also reveals that men, on average, are more narcissistic than women.
\end{abstract}

Copy Right, IJAR, 2017,. All rights reserved.

\section{Introduction:-}

In present scenario men are becoming more conscious about their looks and grooming as indicated by the fast narrowing gap between men and women customers opting for salon services (Indian Beauty and Make-up Annual Survey, beaupal.com 2015-16). One of the major evolutions is that beauty products are no longer restricted to women; men have taken to grooming and preening as well. The rise in the number of men's salon these days, bears testament to this fact. Services like manicure, pedicure, facial, and hair styling, which were once exclusively for women, have become part and parcel of men's grooming routine too (Retrieved from, cosmotechexpoindia). The survey also indicates a rise in men's population availing salon services and challenges past reports which claimed that 85 per cent of salon revenues come from the women population. Survey asserts (beaupal.com) these figures may not stand true in today's times and estimates that men's population may have risen to contribute as high as 20-25 per cent of a salon's revenue. Imagine a country where everyone acts like a reality show contestant obsessed with power, status and appearance, and is comfortable manipulating others for their personal gain. "I'm here to win, not make friends," would be the national motto.

According to some researchers, that is precisely where America is heading. Self-esteem is on the rise, with 80 percent of middle-school students scoring higher in self-esteem in 2006 than the average middle-school student in 1988, according to one study (in the Review of General Psychology, Vol. 14, No. 3, 2006). Among college students, 
subclinical levels of narcissism have steadily risen since the 1970s, other studies suggest. And though the diagnosis may be dropped from the Diagnostic and Statistical Manual of Mental Disorders (see Narcissism and the DSM), young people are much more likely than older adults to have ever experienced Narcissistic Personality Disorder, according to a large-scale epidemiological study published in the Journal of Clinical Psychiatry (Vol. 67, No. 7, 2006).

The American Psychiatric Association (APA) defines NPD in the Diagnostic and Statistical Manual of Mental Disorders-5 (DSM-5; APA, 2013) as "a pervasive pattern of grandiosity (in fantasy and behavior), need for admiration, and lack of empathy, beginning by early adulthood and present in a variety of contexts" (p. 645). Although this definition of narcissism is linked to the clinical conceptualization of NPD, the personality attribute of narcissism exists on a continuum that ranges from mild to extremely maladaptive manifestations (Raskin \& Hall, 1979; Samuel \& Widiger, 2008) and is frequently investigated by social and personality psychologists as a personality trait, not as a personality disorder (e.g., Miller \& Campbell, 2008).

Buffalo, N.Y. (March, 2015) - With three decades of data from more than 475,000 participants, a new study on narcissism from the University at Buffalo School of Management reveals that men, on average, are more narcissistic than women. Forthcoming in the journal Psychological Bulletin, the study compiled 31 years of narcissism research and found that men consistently scored higher in narcissism across multiple generations and regardless of age. "Narcissism is associated with various interpersonal dysfunctions, including an inability to maintain healthy longterm relationships, unethical behavior and aggression," says lead author Emily Grijalva, PhD, assistant professor of organization and human resources in the UB School of Management.

NPD has a high rate of comorbidity with other mental disorders (Paris \& Joel, 2014). Individuals with NPD are prone to bouts of depression, often meeting criteria for co-occurring depressive disorders (Berger \& FK, 2014). In addition, NPD is associated with bipolar disorder, anorexia, and substance use disorders, especially cocaine. As far as other personality NPD has a high rate of comorbidity with other mental disorders (Paris \& Joel, 2014). Individuals with NPD are prone to bouts of depression, often meeting criteria for co-occurring depressive disorders (Berger \& FK, 2014).

\section{Appearance and Narcissism:-}

Several academic studies have found evidence that people with dark triad personalities are judged as slightly betterlooking than average on first sight (Carter, Gregory Louis, Anne C. Campbell, Steven Muncer, 2013). Two studies have determined that this is because people with dark triad traits put more effort into their appearance, and the difference in attractiveness disappears when "dressed down" with bland clothing and without make up (Holtzman\& Nicholas, 2012). Two more studies found that only narcissistic subjects were judged to be better-looking, but the other dark triad traits of machiavellianism and psychopathy had no correlation with looks (Back, Schmuckle \& Egloff, 2010).

Dr. Peter Rentfrow found that narcissism does have a distinct physical signature, and can be detected from physical appearance alone, a psychologist at the University of Cambridge, and one of the team that carried out the study (2008).

For women, key markers included showing cleavage, having plucked eyebrows and wearing make-up. For men, a muscular physique was rated as a key indicator, whereas wearing glasses was a sign of not being narcissistic (Peter Rentfrow, 2008).

"Our exploratory analyses suggest that narcissism is associated with a neat, organised appearance, flashy, revealing clothing, greater adornment like make-up, and expensive, stylish clothes," say the researchers, whose study is to appear in the Journal of Research in Personality (2008).

These results suggest that narcissists do seem to alter their appearance, consciously or unconsciously, in a way that reflects their appearance-oriented motives.

The image that narcissists create appears to capture the unique constellation of personality traits characteristic of narcissism. Narcissism is associated with vanity, exhibitionism, and status-seeking (S Vazire, Peter J. Rentfrow \& Samuel D. Gosling, 2008). 
The findings show that these values are reflected in narcissists' physical appearance - in the clothes they wear, the effort they put into their appearance, and their less-inhibited display of their bodies.

\section{Group differences (Narcissism, Machiavellianism, and Psychopathy):-}

The most pronounced group difference is in gender: numerous studies have shown that men tend to score higher than women on narcissism (Twenge, Jean; Konrath, Sarah; Foster, Joshua; Campbell \& Keith, 2008), Machiavellianism (Dahling, J.J.; Whitaker, B.G.; \& Levy, 2008), and psychopathy (Cale, E.M.; \&Lilienfeld, 2002), although the magnitude of the difference varies across traits and the measurement instruments used. One interesting finding related to narcissism - albeit one based on non-representative samples-is that while men continue to score higher than women, it seems that the gender gap has shrunk considerably when comparing cohort data from 1992 and 2006. More specifically, the aforementioned findings indicate that there has been a general increase in levels of narcissism over time among college students of both sexes, but comparatively, the average level of narcissism in women has increased more than the average level of narcissism in men (Twenge, Jean; Konrath, Sarah; Foster, Joshua; Campbell, Keith; Bushman \& Brad, 2008).

There is far less information available on race differences in dark triad traits, and the data that is available is not representative of the population at-large. For instance, a 2008 research study using undergraduate participants found that Caucasians reported higher levels of narcissism relative to Asians (Trzesniewski, K.H.; Donnellan\& M.B., 2008). Similarly, another 2008 study using undergraduate participants found that Caucasians tended to score slightly higher than non-Caucasians on Machiavellianism (Dahling, J.J.; Whitaker, B.G.; Levy \& P.E., 2008). When attempting to discern whether there are ethnic differences in psychopathy, researchers have addressed the issue using different measurement instruments (e.g., the Self-Report Psychopathy Scale and The Psychopathic Personality Inventory), but no race differences have been found regardless of the measure used (Lander, G.C.; Lutz-Zois, C.J.; Rye, M.S.; Goodnight \& J.A., 2012). Additionally, when comparing Caucasians and African Americans from correctional, substance abuse, and psychiatric samples-groups with typically high prevalence rates of psychopathy - researchers again failed to find any meaningful group differences in psychopathy. In summary, there is some sparse evidence that Caucasians tend to score higher on measures of narcissism and Machiavellianism than other ethnicities, while no evidence exists for race differences in Psychopathy (Skeem, J.L.; Edens, J.F.; Camp, J.; Colwell \& L.H., 2004).

The focal variable when analyzing generational or cohort differences in dark triad traits has tended to be narcissism, arising from the hypothesis that so-called "Generation Me" or "Generation Entitlement" would exhibit higher levels of narcissism than previous generations. Indeed, based on analyses of responses to the Narcissistic Personality Inventory collected from over 16,000 U.S. undergraduate students between 1979 and 2006, it was concluded that average levels of narcissism had increased over time (Twenge, Jean; Konrath, Sarah; Foster, Joshua; Campbell, Keith; Bushman \& Brad, 2008). Similar results were obtained in a follow-up study that analyzed the changes within each college campus (Twenge, J.M.; Campbell \& W.K., 2010).

\section{Methodology:-}

Sample:-

Participants in this study were 104 adolescents and 80 young adults are taken from a convenience sample of Varanasi, Mau and Azamgarh districts of Uttar Pradesh India.

\section{Sample distribution:-}

\begin{tabular}{|c|c|c|c|c|c|}
\hline \multirow{2}{*}{ Appearance status } & \multicolumn{4}{|c|}{ Age Status } & \multirow{2}{*}{ Total } \\
\cline { 2 - 5 } & \multicolumn{2}{|c|}{ Adolescents } & \multicolumn{2}{|c|}{ Young adults } & \\
\cline { 2 - 5 } & Male & Female & Male & Female & \\
\hline Parlor going & 28 & 23 & 20 & 20 & 91 \\
\hline Non- parlor going & 24 & 29 & 20 & 20 & 93 \\
\hline Total & 52 & 52 & 40 & 40 & 184 \\
\hline
\end{tabular}

\section{Instruments:-}

The survey instrument consists twenty-three question (exclusive of demographic questions) paper pencil survey, comprised of two distinct sections includes first is check-list and second is Narcissistic Personality Inventory, instruments are described below. 
1. Check-List: Check- list consists of seven Yes/No type questions which use to determine appearance status of participant, whether participant have parlor going or non-parlor going tendency.

2. Narcissistic Personality Inventory-16:The Narcissistic Personality Inventory-16 (NPI-16) is a shortened form of the NPI-40 for measuring subclinical narcissism that has shown meaningful face, internal, discriminant, and predictive validity. A further refinement of earlier NPI versions developed by Raskin and Hall containing 80 and 54 items, respectively, the shortened Narcissistic Personality Inventory-40 (NPI-40) was subjected to three different studies by its authors in 1988 to analyze it's construct validity, and has been used and examined in many studies to date. Daniel Ames developed the NPI-16, a further shortened version based on the NPI-40. In Raskin \& Terry (1988) NPI-40, alpha composite reliability scores of $0.83,0.74,0.80$, and 0.90 were calculated for the Narcissistic Personality Inventory.

Daniel Ames, Paul Rose, \& Cameron P. Anderson (2006) NPI-16, $\alpha=0.72$; mean inter-item correlation $=0.13$; loadings on the first unrotated factor ranged from 0.13 to 0.66 with the first factor capturing 19.9 percent of variance; correlated with the NPI-40 at $r=0.90(p<0.01)$.

\section{Procedure:-}

The survey questionnaire test (Check-list, NPI-16) was administered to the participants with proper instruction. Data was collected and scoring was done with the help of scoring keys. Then the scores of participants were tabulated for the further analysis to make inferences from the data by using appropriate statistical package.

\section{Statistical Analysis:}

First the Descriptive Statistics was used to analyze the participants' minimum and maximum scores, mean and standard deviation after that Two-Way Analysis of Variance used to analyze main and interaction effects of Age status, Gender status and Appearance status on Narcissism and for analysis of the data Statistical significance was established at the level of $\mathrm{P} \leq 0.05$. The data were processed using IBM SPSS 24.0 software.

\section{Results:-}

In the present research work data analysis has been done with the help of descriptive and interactional (ANOVA) statistics. Results as per statistical analysis are as follows:

Table-1:-Mean and S.D. of score for Age status*Gender status*Appearance status $(2 \times 2 \times 2)$ on Narcissism.

\begin{tabular}{|c|c|c|c|c|c|}
\hline AGE STATUS & GENDER STATUS & APPEARANCE STATUS & $\mathrm{N}$ & Mean & S.D. \\
\hline \multirow[t]{9}{*}{ Adolescents } & \multirow[t]{3}{*}{ Male } & Parlor Going & 28 & 6.36 & 2.57 \\
\hline & & Non Parlor Going & 24 & 4.92 & 2.08 \\
\hline & & Total & 52 & 5.69 & 2.45 \\
\hline & \multirow[t]{3}{*}{ Female } & Parlor Going & 23 & 5.87 & 1.77 \\
\hline & & Non Parlor Going & 29 & 4.59 & 1.97 \\
\hline & & Total & 52 & 5.15 & 1.97 \\
\hline & \multirow[t]{3}{*}{ Total } & Parlor Going & 51 & 6.14 & 2.24 \\
\hline & & Non Parlor Going & 53 & 4.74 & 2.01 \\
\hline & & Total & 104 & 5.42 & 2.22 \\
\hline \multirow[t]{9}{*}{ Young Adults } & \multirow[t]{3}{*}{ Male } & Parlor Going & 20 & 6.35 & 1.93 \\
\hline & & Non Parlor Going & 20 & 4.55 & 2.21 \\
\hline & & Total & 40 & 5.45 & 2.24 \\
\hline & \multirow[t]{3}{*}{ Female } & Parlor Going & 20 & 5.10 & 2.38 \\
\hline & & Non Parlor Going & 20 & 3.50 & 2.21 \\
\hline & & Total & 40 & 4.30 & 2.41 \\
\hline & \multirow[t]{3}{*}{ Total } & Parlor Going & 40 & 5.73 & 2.23 \\
\hline & & Non Parlor Going & 40 & 4.03 & 2.25 \\
\hline & & Total & 80 & 4.88 & 2.38 \\
\hline \multirow[t]{5}{*}{ Total } & \multirow[t]{3}{*}{ Male } & Parlor Going & 48 & 6.35 & 2.30 \\
\hline & & Non Parlor Going & 44 & 4.75 & 2.13 \\
\hline & & Total & 92 & 5.59 & 2.35 \\
\hline & \multirow[t]{2}{*}{ Female } & Parlor Going & 43 & 5.51 & 2.09 \\
\hline & & Non Parlor Going & 49 & 4.14 & 2.12 \\
\hline
\end{tabular}




\begin{tabular}{|l|c|c|c|c|c|}
\hline \multirow{3}{*}{ Total } & Total & 92 & 4.78 & 2.20 \\
\cline { 2 - 5 } & \multirow{4}{*}{} & Parlor Going & 91 & 5.96 & 2.23 \\
\cline { 2 - 5 } & & Non Parlor Going & 93 & 4.43 & 2.13 \\
\cline { 2 - 5 } & & Total & 184 & 5.18 & 2.31 \\
\hline
\end{tabular}

Table-2:- Summary of 2 × 2 × 2 (Age status*Gender status*Appearance status) ANOVA on Narcissism.

\begin{tabular}{|c|c|c|c|c|c|}
\hline Dependent Variable & Source & $\begin{array}{l}\text { Sum of } \\
\text { Squares }\end{array}$ & df & $\begin{array}{l}\text { Mean } \\
\text { Square }\end{array}$ & $\mathrm{F}$ \\
\hline \multirow[t]{8}{*}{ Scores on NPI } & Age Status & 13.99 & 1 & 13.99 & 3.00 \\
\hline & Gender Status & 27.36 & 1 & 27.36 & $5.87 *$ \\
\hline & Appearance status & 105.54 & 1 & 105.54 & $22.65 * *$ \\
\hline & $\begin{array}{c}\text { Age Status*Gender } \\
\text { Status }\end{array}$ & 6.18 & 1 & 6.18 & 1.33 \\
\hline & $\begin{array}{c}\text { Age Status*Appearance } \\
\text { status }\end{array}$ & 1.29 & 1 & 1.29 & 0.28 \\
\hline & $\begin{array}{c}\text { Gender Status* } \\
\text { Appearance status }\end{array}$ & 0.36 & 1 & 0.36 & 0.08 \\
\hline & $\begin{array}{l}\text { Age Status*Gender } \\
\text { Status*Appearance } \\
\text { status }\end{array}$ & 0.01 & 1 & 0.01 & 0.00 \\
\hline & Error & 820.24 & 176 & 4.66 & \\
\hline
\end{tabular}

Note $=* * \mathrm{P} \leq 0.01, * \mathrm{P} \leq 0.05$

\section{Graph-1}

\section{Narcissism (mean value) by Age status*Gender status*Appearance}

\section{status}

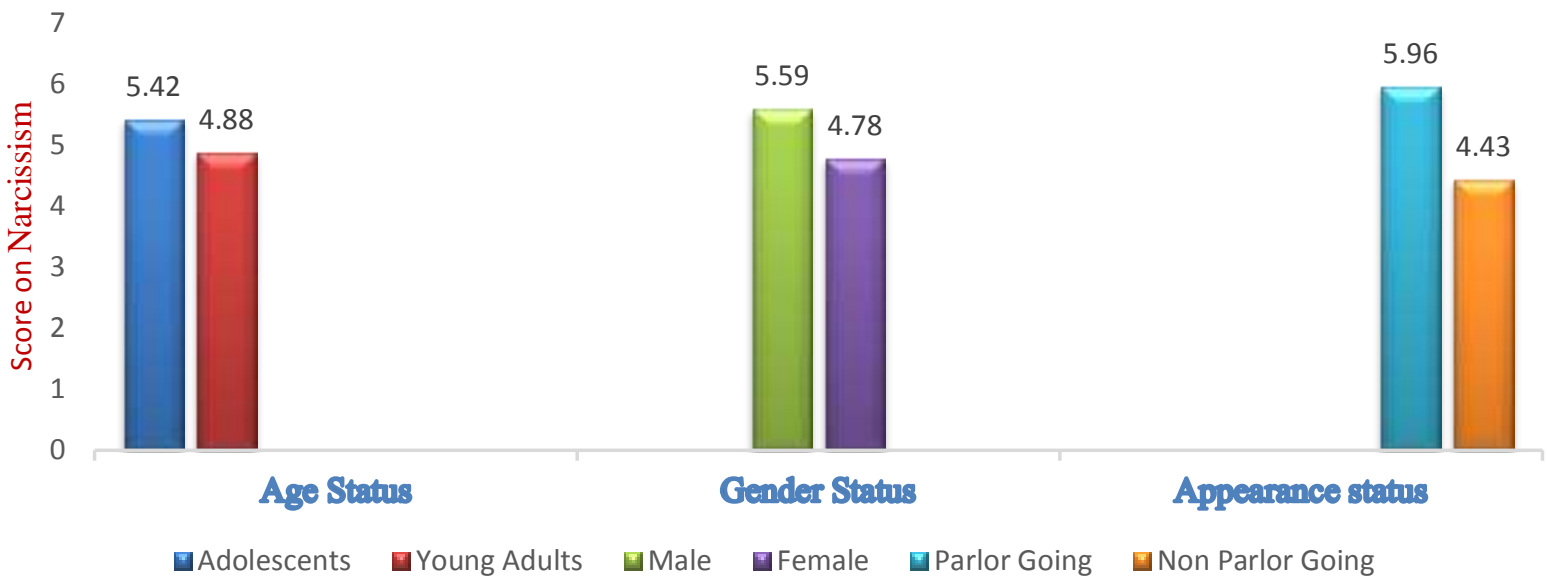

Calculation of Mean, S.D. and Two-Way ANOVA has been analyzed for the verification of hypothesis. For the dimension Narcissism, Table-1 explores that Mean and S.D. of Adolescents $(\mathrm{M}=5.42, \pm 2.23)$ and Young adults $(\mathrm{M}=4.88, \pm 2.34)$ were found almost same and Table-2 reveals that between Age status [F-ratio $(1,176)=3.00 \mathrm{NS}$ ] was found insignificant. Therefore, Age Status is not affecting the variable Narcissism.

For The Gender Status Table-1 reveals that Mean and S.D. of Male $(M=5.59, \pm 2.35)$ and Female $(M=4.78, \pm 2.20)$ and Table-2 show that between Gender status [F-ratio $(1,176)=5.87, \mathrm{P}<0.05]$ was found significant at 0.05 level. Thus Gender status is partially affecting variable Narcissism and Graph-1 represents that mean score of male on Narcissism is higher than female. Table-1 also disclose that Appearance status is profoundly affecting Narcissism and Graph-1 display that Narcissism is higher in parlor going than non-parlor going. Mean and S.D. of Parlor Going 
$(\mathrm{M}=5.96, \pm 2.23)$ and Non parlor going $(\mathrm{M}=4.43, \pm 2.13)$ and Table-2 display that between Appearance status [F-ratio $(1,176)=22.65, \mathrm{P}<0.01]$ was found significant at 0.01 level .

There is Table- 2 manifest that the interactional relationship between Age status and Gender status [F-ratio $(1,176)=$ $1.33 \mathrm{NS}$ ] was found not significant, that is Age status and Gender status are not jointly affecting the variable Narcissism.

Table-2 also confirms that Age status and Appearance status are mutually not influencing Narcissism. There is interactional relationship between age status and Appearance status [F-ratio $(1,176)=0.28 \mathrm{NS}$ ] was found insignificant.

The interactional relationship between Gender status and Appearance status [F-ratio $(1,176)=0.08$ NS] was found inconsequential as mentioned in Table-2. That is Gender status and Appearance status are together not affecting the variable Narcissism.

Moreover, Table-2 also communicates that the interactional relationship between Age status, Gender status and Appearance status [F-ratio $(1,176)=0.00 \mathrm{NS}$ ] was found inconsiderable, which means Age status, Gender status and Appearance status are jointly not influencing the Narcissism.

\section{Discussion:-}

This exploratory study seeks to examine the main and interaction effect of Narcissism with appearance status (Parlor going/Non parlor going) among male-female adolescents and young adults. Fundamentally, the finding reveals that men, on average, are more narcissistic than women. This result suggests that compared with women, men are more likely to exploit others and to believe that they themselves are special and therefore entitled to privileges and compared with women men exhibit more assertiveness, motivation to lead, and a desire for power and authority over others. This finding is consistent in their practical significance with previous studies conducted by Buffalo, N.Y. (March, 2015); Emmons (1984); Raskin and Terry (1988); Ackerman et al.'s (2011), and Grijalva, Emily; Newman, Daniel A.; Tay, Louis; Donnellan, M. Brent; Harms, Peter D. The finding also reveals that narcissism is high in the people having parlor going tendencies, we found that narcissism does have a distinct physical signature, and can be detected from physical appearance alone, the finding of the present study was found to be consistent with the previous study of SimineVazire, Laura P. Naumann, Peter J. Rentfrow, Samuel D. Gosling (University of Cambridge, 2008).

\section{Conclusion:-}

Because this study functions as an exploratory foundation to include the construct of appearance status (Parlor going/Non parlor going) among male-female adolescents and young adults as a potential variable in Narcissism, it serves to contribute to the ongoing investigation into the relationships between Narcissism and Appearance categories (Parlor going/Non parlor going, Adolescents/Young adults and Male/Female). Fundamentally, the finding reveals that men, on average, are more narcissistic than women. This result suggests that compared with women, men are more likely to exploit others and to believe that they themselves are special and therefore entitled to privileges and compared with women men exhibit more assertiveness, motivation to lead, and a desire for power and authority over others, finding also reveals that narcissism is high in the people having parlor going tendencies, (Buffalo, N.Y., 2015; Emmons, 1984; Raskin and Terry,1988). This research does contribute some indication as to why Parlor going individuals report high Narcissism, why young adults are more agreeable than adolescents, why females more suffers with anxiety, anger, envy, guilt, and depressed mood than male and so many questions. It is hoped that the contribution of the present research, in combination with prior and future studies like it, will promote a more thorough understanding of narcissistic personality and how it operates within the relational domain.

\section{Limitations:-}

Like all research that uses self-report measures, the results of this study may have been affected by common methods bias including social desirability bias and consistency motif. Small sample used in the present study limit the generalization of present findings and male female ratio in this study was also unequal. 


\section{Acknowledgments:-}

The author appreciates all those who participated in the study and helped to facilitate the research process.

\section{Conflict of Interests:-}

The author declared no conflict of interests.

\section{References:-}

1. Ames, Daniel R., Rose, Paul, and Anderson, Cameron P. (2006). The NPI-16 as a short measure of narcissism. Journal of Research in Personality, 40, 440-450.

2. Back, S., \& Egloff. (2010). Why are narcissists so charming at first sight? Decoding the narcissism-popularity link at zero acquaintance. Journal of Personality and Social Psychology, 132-145. doi:10.1037/a0016338

3. Balsis S, S. D. (2009). Revising the personality disorder diagnostic criteria for Revising the personality disorder diagnostic criteria for DSM-5:Consider the later life context. American Journal of Orthopsychiatry.(79), 452-460.

4. Berger, F. (2014). Medical Encyclopedia: Narcissistic personality disorder. MedlinePlus: U.S. National Library of Medicine.

5. BUFFALO, N. (2015, March 4). Men tend to be more narcissistic than women. Retrieved from University of buffalo (News Center): http://www.buffalo.edu/news/releases/2015/03/009.html

6. Campbell, W. K., \& Miller, J. D. (2011). The Handbook of Narcissism and Narcissistic Personality Disorder: Theoretical Approaches, Empirical Findings and Treatments. John Wiley \& Sons.

7. Carter, G. L. (2013). The Dark Triad personality:Attractiveness to women. Personality and Individual Differences.

8. Dahling, J., Whitaker, B., \& Levy, P. (2008). The development and validation of a new Machiavellianism scale. Journal of Management, 35, 219-257. doi:10.1177/0149206308318618

9. Diagnostic and statistical manual of mental disorders : DSM-5 (5th ed.). (2013). Washington: American Psychiatric Publishing.

10. Digman, J. M. (1990). Personality structure: Emergence of the five-factor model. Annual Review of Psychology, 417-440. doi:10.1146/annurev.psych.41.1.417

11. Dingfelder, S. (2011, February). Narcissism and the DSM. 42, 67. American Psychological Association. Retrieved from http://www.apa.org/monitor/2011/02/narcissism-dsm.aspx

12. Epstein, M., Poythress, N., \& Brandon, K. (2006). "The Self-Report Psychopathy Scale and Passive Avoidance Learning A Validation Study of Race and Gender Effects. Assessment., pp. 197-207.

13. Grijalva E, N. D. (2015). Gender differences in narcissism: A metaanalytic review. Psychological Bulletin, 261. doi:10.1037/a0038231

14. Holtzman, N. S. (2012). People With Dark Personalities Tend to Create a Physically Attractive Veneer. Sage Journal, 4(4), 461-467. doi:10.1177/1948550612461284

15. IANS. (2016, September 25). Men increasingly availing salon services. Retrieved from BeauPal.com: http://in.shafaqna.com/EN/03191126

16. Jason J. Dahling, B. G. (2008). The Development and Validation of a New Machiavellianism Scale. Journal of Management, 35, 219-257. doi:10.1177/0149206308318618

17. Lander, G., Lutz-ZOis, C., Rye, M., \& Goodnight, J. (2012). The differential association between alexithymia and primary versus secondary psychopathy. Personality and Individual Differences, 50(1), 45-50. doi:10.1016/j.paid.2011.08.027

18. Paris, J. (2014). Modernity and narcissistic personality disorder. Personality:Disorders Theory, Research, and Treatment, 5(2), 220. doi:10.1037/a0028580

19. Raskin, R. \&. (1988). A principal-components analysis of the Narcissistic Personality Inventory and further evidence of its construct validity. Journal of Personality and Social Psychology, 54, 890-902.

20. Raskin, R. N. (1979). A Narcissistic Personality Inventory. Psychological Reports, 45(2), 590-590.

21. Rentfrow, D. P. (2008, Jul 09). Beware of the narcissist: Plucked eyebrows may reveal a personality disorder. Retrieved from The Telegraph: http://www.telegraph.co.uk/news/newstopics/howaboutthat/2275331/Bewareof-the-narcissist-Plucked-eyebrows-may-reveal-a-personality-disorder.html

22. Skeem, J. L., Polaschek, D. L., Patrick, C. J., \& Lilienfeld, S. O. (2001). Psychopathic Personality: Bridging the Gap Between Scientific Evidence and Public Policy. Psychological Science in the Public Interest, 95-162. doi: $10.1177 / 1529100611426706$

23. Skeem, J., Edens, J., Camp, J., \& Colwell, L. (2004). Are there ethnic differences in levels of psychopathy? A 
meta-analysis. Law and human behavior, 28(5), 505-527. doi:10.1023/b:lahu.0000046431.93095.d8

24. Trzesniewski, K. \&. (2010). Rethinking "Generation Me": A study of cohort effects from. Perspectives in Psychological Science, 58-75.

25. Trzesniewski, K., \& Donnellan, M. (2008). Do today's young people really think they are so extraordinary? An examination of secular trends in narcissism and selfenhancement. Psychological Science, 19(2), 181-188. doi:10.1111/j.14679280.2008.02065

26. Trzesniewski, K., \& Donnellan, M. (2010). Rethinking "Generation Me" a study of cohort effects from 19762006. Perspectives on Psychological Science, 5(1), 58-75. doi:10.1177/1745691609356789

27. Twenge, J. \&. (2009). The narcissism epidemic: Living in the age of entitlement. New York: Free Press.

28. Twenge, J., \& Campbell, W. (2010). Birth Cohort Differences in the Monitoring the Future Dataset and Elsewhere Further Evidence for Generation Me - Commentary on Trzesniewski \& Donnellan. Perspectives on Psychological Science, 5(1), 81-88. doi:10.1177/1745691609357015

29. Twenge, J., \& Foster, J. (2008). Mapping the scale of the narcissism epidemic: Increases in narcissism 20022007 within ethnic groups. Journal of Research in Personality, 42(6), 1619-1622. doi:10.1016/j.jrp.2008.06.014.

30. Twenge, J., Konrath, S., Foster, J., Campbell, K., \& Bushman, B. (. (2008). Egos inflating over time: a cross-temporal meta-analysis of the Narcissistic personality inventory. Journal of Personality, 76(4), 875-902. doi:10.1111/j.1467-6494.2008.00507

31. Twenge, J., Konrath, S., Foster, J., Campbell, K., \& Bushman, B. (2008). Egos inflating over time: a cross-temporal meta-analysis of the Narcissistic personality inventory. Journal of Personality, 76(4), 645-646. doi:10.1111/j.1467-6494.2008.00507.x 